\title{
Sea Surface Salinity Seasonal Variability in the Tropics from Satellites, Gridded In Situ Products and Mooring Observations
}

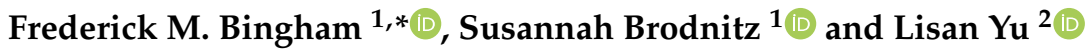 \\ 1 Center for Marine Science, University of North Carolina Wilmington, Wilmington, NC 28403-5928, USA; \\ brodnitzs@uncw.edu \\ 2 Department of Physical Oceanography, Woods Hole Oceanographic Institution, Woods Hole, MA 02543, USA; \\ lyu@whoi.edu \\ * Correspondence: binghamf@uncw.edu; Tel.: +1-910-962-2383
}

Citation: Bingham, F.M.; Brodnitz, S.; Yu, L. Sea Surface Salinity Seasonal Variability in the Tropics from Satellites, Gridded In Situ Products and Mooring Observations. Remote Sens. 2021, 13, 110. https://doi.org/ $10.3390 /$ rs13010110

Received: 30 November 2020 Accepted: 29 December 2020 Published: 31 December 2020

Publisher's Note: MDPI stays neutral with regard to jurisdictional clai$\mathrm{ms}$ in published maps and institutional affiliations.

Copyright: (C) 2020 by the authors. Licensee MDPI, Basel, Switzerland. This article is an open access article distributed under the terms and conditions of the Creative Commons Attribution (CC BY) license (https:// creativecommons.org/licenses/by/ $4.0 /)$.

\begin{abstract}
Satellite observations of sea surface salinity (SSS) have been validated in a number of instances using different forms of in situ data, including Argo floats, moorings and gridded in situ products. Since one of the most energetic time scales of variability of SSS is seasonal, it is important to know if satellites and gridded in situ products are observing the seasonal variability correctly. In this study we validate the seasonal SSS from satellite and gridded in situ products using observations from moorings in the global tropical moored buoy array. We utilize six different satellite products, and two different gridded in situ products. For each product we have computed seasonal harmonics, including amplitude, phase and fraction of variance $\left(R^{2}\right)$. These quantities are mapped for each product and for the moorings. We also do comparisons of amplitude, phase and $\mathrm{R}^{2}$ between moorings and all the satellite and gridded in situ products. Taking the mooring observations as ground truth, we find general good agreement between them and the satellite and gridded in situ products, with near zero bias in phase and amplitude and small root mean square differences. Tables are presented with these quantities for each product quantifying the degree of agreement.
\end{abstract}

Keywords: sea surface salinity; seasonal variability; satellite validation; harmonic analysis; mooring observations

\section{Introduction}

Sea surface salinity (SSS) has been observed by satellite for over 10 years since the launch of the Soil Moisture and Ocean Salinity (SMOS; [1]) instrument in 2009. Since then two other satellites have been launched by NASA that have measured SSS from space, Aquarius [2] and Soil Moisture Active Passive (SMAP) [3]. Validation of these datasets has occurred in a number of contexts by comparison with in situ data [4-13]. Typically, individual satellite measurements are compared with nearby in situ measurements such as individual Argo floats [4], or more commonly with gridded Argo products such as that of Roemmich et al. [14] or the global Hybrid Coordinate Ocean Model (HYCOM) [3]. Problems exist with this type of comparison, however. Individual float measurements are usually made at $5 \mathrm{~m}$ depth, as compared to $1-2 \mathrm{~cm}$ for the satellites [15], and are spatially and temporally sparse compared to the satellite measurements. Gridded Argo products have their own uncertainty related to the sparse sampling and the gridding process [16].

In many regions of the ocean, the most important time scale is seasonal [17-22]. This is especially true in the tropics where the intertropical convergence zone (ITCZ) migrates seasonally in the meridional direction [23-25] bringing with it increased precipitation [26] and the seasonal translation of the North Equatorial Countercurrent front. Thus, SSS has been observed to have large seasonal variations in the tropics, especially north of the equator in the Pacific and Atlantic basins $[17,18,22,27,28]$ where the ITCZ is present and as a result of strong river discharge into the tropical Atlantic. 
The global tropical moored buoy array (GTMBA) is a vast network of moorings stretching across all the ocean basins (Figure 1). It was set up starting in the 1980s to measure variations related to El Niño in the Pacific, but has since expanded to the Indian and Atlantic basins [29]. These moorings measure quantities such as wind, precipitation, humidity, currents, sea surface temperature, subsurface temperature and, most importantly for the current study, SSS. The high-quality standards, long record duration (some over 20 years-Figure 1) and location of the buoys in this array make them ideal platforms for validating satellite SSS measurements. Several groups have been making use of the GTMBA for this purpose $[4,5,7,12,13,30]$. However, to date there has been little explicit comparison of mooring and satellite SSS data at a seasonal time scale. Bingham et al. [17] used the mooring data to compute annual harmonics, but made no comparison to satellites as such data did not exist at the time.
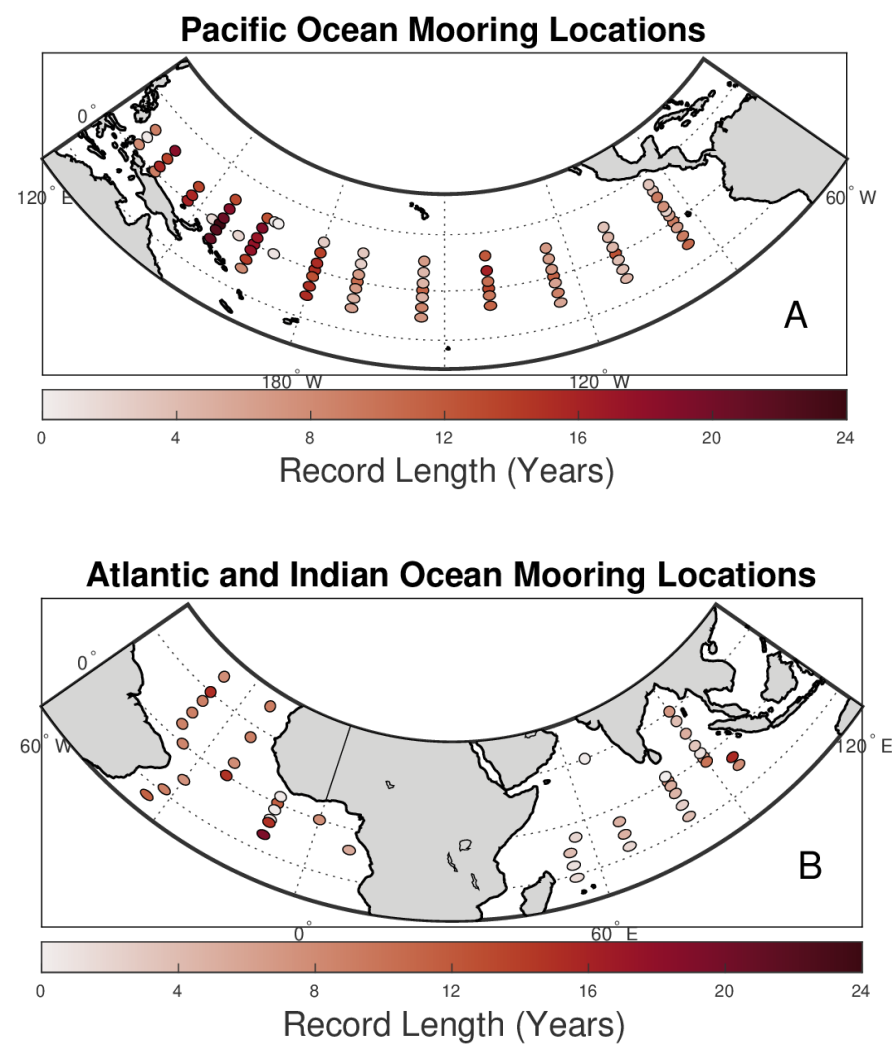

Figure 1. The Global Tropical Moored Buoy Array. (A) The array is called "TAO" in the eastern and central Pacific, "TRITON" in the western Pacific, (B) "PIRATA" in the Atlantic and "RAMA" in the Indian ocean. Note, some sites are not currently operational, especially in the western Pacific. Symbol colors correspond to the length of the record in years, with a scale at the bottom. The record length refers to the total number of hourly measurements regardless of gaps.

Bingham and Lee [21] found that a decorrelation scale of 80-100 days, corresponding to the seasonal time scale, was the most important one for about $1 / 3$ of the global ocean, and that it was concentrated in the tropics. Bingham et al. [17,18], using sparse historic and early Argo data, found large amplitude seasonal harmonics in the tropical oceans. This result was verified by comparison to GTMBA data from the Pacific basin available at the time. Such large amplitude seasonal harmonics were also found by Boyer \& Levitus [19] and Yu et al. [20]. The most recent estimates of Yu et al. [20] using multiple satellite datasets found typical seasonal amplitudes of up to 0.5 in the tropics, with higher values in regions such as the Amazon and Congo River plumes.

We use data from the three satellites mentioned above: SMOS, SMAP and Aquarius. Although they use the same frequency of radiation to make their estimate, the satellites have very different configurations and ways of forming an image to retrieve values of SSS 
(see references in Table 1 and Reul et al. [31] for a summary). Thus, we use two different level 3 (L3) SMOS products, SMOS Barcelona Expert Center (BEC) and SMOS Centre Aval de Traitment des Donées (CATDS), one L4 synthesis product, Climate Change Initiative (CCI), one L3 Aquarius product and two L3 SMAP products, SMAP Jet Propulsion Lab (JPL) and SMAP Remote Sensing Systems (RSS). The various products have different ways of averaging or interpolating to get to a final version. Finally, we also examine two commonly used gridded in situ products, Scripps Institution of Oceanography (SIO) and EN4 [32]. These compilations serve as calibration points or first guess fields used in the retrieval process for some of the satellite products [33]. In this paper we directly compare all of these products to the mooring data at the seasonal time scale, and inter-compare the two SMOS and two SMAP products using the same methods. In an operational sense, the intent of this paper is to provide a guide to the user as to the advantages and disadvantages of different products when studying seasonal variability of SSS. In some products we will find that the seasonal time scale is suppressed relative to the moorings as ground truth. In others, the seasonal time scale is enhanced due to the way the measurement is generated or computed.

This paper is closely related to Yu et al. [20], and has a similar motivation. That paper is a revisit of Boyer \& Levitus [19] and similar works using the more modern datasets now available. There are several distinctions between the work here and that of Yu et al. [20]. Yu et al.'s [20] study is done using the 2018 World Ocean Atlas data as the "truth", whereas here we use the GTMBA moorings. Yu et al.'s [20] study uses only 3 years of records for computing harmonics, whereas we use all the satellite data and mooring data available, with up to $20+$ years of record lengths for the moorings and up to 9 years for the satellites (Table 1). We explicitly compare amplitudes, phases and fractions of variance between the moorings and satellite/gridded in situ products in a more detailed way than is done in Yu et al. [20]. Our focus is on individual moorings as opposed to the basin-scale patterns examined in Yu et al. [20]. Despite all of these differences, it should be noted that we use many of the same satellite datasets that are found in Yu et al. [20], and that the results we find here are similar to the ones found by Yu et al. [20].

The structure of the paper is as follows. In Section 2 we introduce the datasets we use, and the harmonic analysis method. In Section 3 we present maps of annual amplitude and phase derived from the moorings and a couple of the satellite products and compare amplitudes, phases and fractions of variance in a set of scatterplots. We also compute deviations of each product from the mooring-derived values. In Section 4 we discuss these results in the context of previous studies, and in Section 5 we conclude.

\section{Data and Methods}

All values of salinity in this paper are in practical salinity using the 1978 practical salinity scale. Practical salinity is unitless, and, following Millero [34], we do not use terms such as "psu". The terms "annual" and "seasonal" are used synonymously in this paper and refer to quantities that vary with a period of one year.

\subsection{Datasets Used}

As stated above, we make use of nine main SSS datasets, two gridded in situ (EN4 and SIO), one in situ moored and six L3 and L4 satellite (Table 1). Information for accessing all datasets is in the Data Availability Statement. Time series of SSS were extracted from the different products at the grid node closest to the location of each mooring. These grid nodes are not located exactly at the sites of the moorings. For the SMAP and SMOS products, the mean distance from grid node to mooring location is about $0.17^{\circ}$. For the Aquarius and SIO products the mean distance is $0.70^{\circ}$. For the EN4 product it is $0.04^{\circ}$. In most cases, the mooring location lies within the footprint of the satellite or the averaging area of the gridded in situ product.

An overview of the methods used to produce the L3 estimates for the satellite datasets from raw brightness temperatures is given by Reul et al. [31]. This reference also describes such things as the repeat period and spatial resolution. 
Table 1. A list of the datasets used in this study showing the time resolution, spatial grid and time span. SMOS: Soil Moisture and Ocean Salinity; BEC: Barcelona Expert Center; CTADS: Centre Aval de Traitment des Donées; CCI: Climate Change Initiative; SMAP: Soil Moisture Active Passive; JPL: Jet Propulsion Lab; RSS: Remote Sensing Systems; SIO: Scripps Institution of Oceanography.

\begin{tabular}{|c|c|c|c|c|}
\hline Dataset & Time Resolution & Spatial Grid & Time Span & References \\
\hline Moorings & Hourly & $\mathrm{N} / \mathrm{A}$ & various & [35] \\
\hline SMOS BEC & $\begin{array}{l}\text { Daily values with a 9-day } \\
\text { running mean }\end{array}$ & $0.25^{\circ}$ & 2011-2019 & {$[9,10,36]$} \\
\hline SMOS CATDS & $\begin{array}{l}\text { 4-day values with a 9-day } \\
\text { running mean }\end{array}$ & $\begin{array}{l}\text { Lon: } 0.2594^{\circ} \\
\text { Lat: varies from } 0.1962^{\circ} \text { to } 1.5341^{\circ}\end{array}$ & 2010-2019 & [37-39] \\
\hline CCI & $\begin{array}{l}\text { Daily values with a 7-day } \\
\text { running mean }\end{array}$ & $\begin{array}{l}\text { Lon: } 0.2594^{\circ} \\
\text { Lat: varies from } 0.1962^{\circ} \text { to } 1.5341^{\circ}\end{array}$ & 2010-2018 & {$[40]$} \\
\hline SMAP JPL & 8-day running mean & $0.25^{\circ}$ & $2015-2020$ & {$[41]$} \\
\hline SMAP RSS (70 km) & 8-day running mean & $0.25^{\circ}$ & $2015-2020$ & {$[3,33]$} \\
\hline Aquarius & $\begin{array}{l}\text { Daily values with a 7-day } \\
\text { running mean }\end{array}$ & $1^{\circ}$ & 2011-2015 & {$[2,8]$} \\
\hline EN4 & Monthly & $1^{\circ}$ & $2000-2018$ & [32] \\
\hline $\mathrm{SIO}$ & Monthly & $1^{\circ}$ & $2004-2020$ & [14] \\
\hline
\end{tabular}

The vertical sampling of the three data types is different. The salinity sensors on the moorings are at $\sim 1 \mathrm{~m}$ depth [35]. Argo floats, which make up the bulk of the observations used in the EN4 and SIO datasets, are sampled about $5 \mathrm{~m}$ depth. Satellite SSS sensors sample the upper 1-2 cm [15].

The computations detailed below using the moorings were repeated with data from only 2010 and after to match the time period when the satellites were operating. The results were very similar, only with less precision due to the use of shorter time series.

\subsection{Harmonic Analysis}

Using a standard harmonic analysis, annual and semiannual harmonic fits were computed for each mooring time series $[17,19,22,42]$ and for each of the other products at the closest gid node to each mooring site. These computations yield amplitudes, phases (month of maximum SSS) and fractions of variance $\left(R^{2}\right)$ associated with both annual and semiannual. We show results for the annual harmonics only in this paper. Semiannual harmonic amplitudes were generally smaller and we omit those results for brevity here, but include some of them in the supplemental materials for completeness (Tables S4-S6).

Harmonic analysis involves fitting each salinity time series to

$$
S=S_{0}+A_{1} \cos \left(\omega_{1} t+\varphi_{1}\right)+A_{2} \cos \left(\omega_{2} t+\varphi_{2}\right)+\epsilon
$$

$\omega_{1}$ is the annual frequency, i.e., $2 \pi$ radians/yr. $\omega_{2}$ is the semiannual frequency, $4 \pi$ radians/yr. $A_{1}\left(A_{2}\right)$ is the amplitude of the (semi)annual harmonic. $\varphi_{1}\left(\varphi_{2}\right)$ is the phase of the (semi) annual harmonic. $t$ is the time. $\mathrm{S}_{0}$ is the mean value of salinity at each location. $\varepsilon$ is a residual to be minimized in the least squares sense by determination of $A_{1}, A_{2}, \varphi_{1}$ and $\varphi_{2}$.

Significance tests for the harmonic fits were carried out for the first and second harmonics separately. The $\mathrm{R}^{2}$ value of each harmonic was calculated with the standard formula

$$
\mathrm{R}^{2}=1-\frac{\text { variance }(\text { data }- \text { fit })}{\text { variance }(\text { data })} .
$$

The f-statistic was then calculated from $\mathrm{R}^{2}$ using the equation

$$
\mathrm{f}=\left(\frac{\mathrm{R}^{2}}{1-\mathrm{R}^{2}}\right) \cdot\left(\frac{n-k-1}{k}\right),
$$

where $n$ is the number of observations (non-null data points in the time series at that location) and $k$ is the number of independent variables, two in the case of looking at 
the annual and semiannual harmonics individually. Then the cumulative F-distribution function was used on the given $\mathrm{f}$-statistic, $n$, and $k$, and fits with values greater than 0.95 were considered significant. The significance was calculated as if all the data points were independent observations. In addition to filtering by significance, we only considered locations where we had at least one year total of data points for a given dataset.

In comparing the amplitudes, phases and $\mathrm{R}^{2}$ values between mooring and products, we used the entirety of each dataset, including possibly nonoverlapping periods. This was done because (1) the computed amplitudes and phases seemed stable as described below, (2) we wanted to increase the significance of the computed fits and (3) many of the moorings were sampled sporadically (e.g., Figure 2A) making determination of overlapping periods computationally cumbersome.
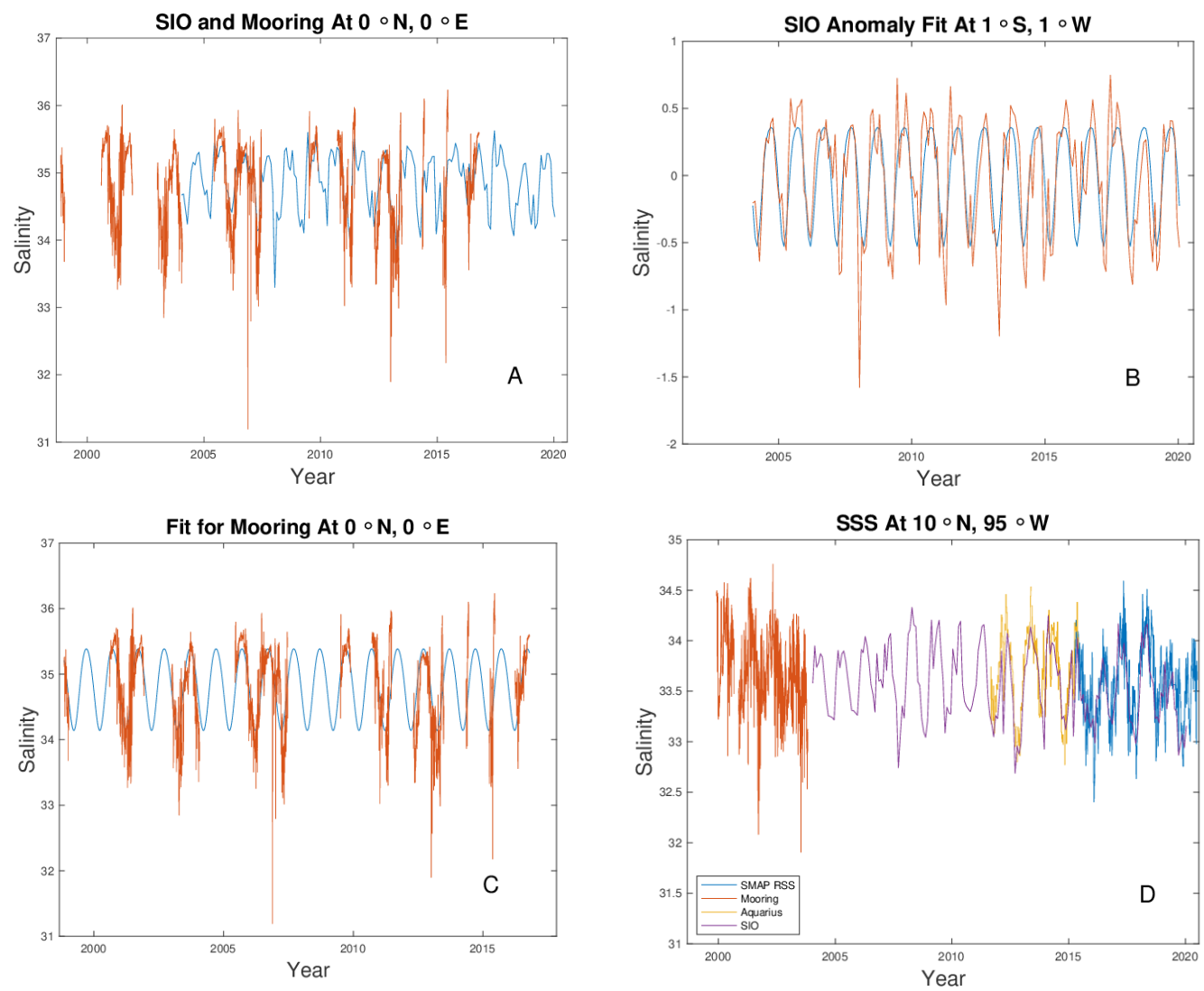

Figure 2. Harmonic fits and observations of sea surface salinity (SSS) at $\left(0^{\circ} \mathrm{N}, 0^{\circ} \mathrm{E}\right)$. (A) Mooring (red) and SIO (blue) observations. (B) SIO anomaly (red) and its harmonic fit (blue). (C) Mooring (red) and its harmonic fit (blue). (D) SSS data from $10^{\circ} \mathrm{N}, 95^{\circ} \mathrm{W}$. Source of data is indicated in the legend at the bottom left.

As an illustration of the method, we show the mooring data, harmonic fit, SIO data and its fit at the mooring site at $\left(0^{\circ} \mathrm{N}, 0^{\circ} \mathrm{E}\right)$. Although there are large gaps in the mooring record (Figure 2A), a major advantage of the harmonic method is that it can make use of such time series. A possible problem with the method is if the amplitude or phase of the seasonal variability changes over time. The SIO data indicate that for this location this is not an issue (Figure 2B). The seasonal maximum or minimum does vary from year to year, but not in a systematic or interannual way. The signal appears phase-locked to the calendar year. The harmonic fits we have done do not depict some of the extreme events in the mooring record (Figure 2C), so in this sense it acts as a low-pass filter. These low SSS values may indicate real events (e.g., [43]). The way they are displayed in the figure tends to exaggerate their importance however, as they generally consist of only a small number of hourly observations. The amplitudes of the two records in Figure 2A-C are similar. The 
peak-to-peak amplitude of the SIO fit is about 0.8 (Figure 2B), whereas that for the mooring is a little larger, about 1.0 (Figure 2C).

We also show data from a different location in the eastern tropical North Pacific (Figure $2 \mathrm{D} ; 10^{\circ} \mathrm{N}, 95^{\circ} \mathrm{W}$ ). There is no fit displayed, but it is clear there is a large annual cycle in all the datasets. The amplitude and phase of that annual cycle is relatively stable, except for the 2015-2016 and 2019-2020 periods.

\section{Results}

\subsection{Amplitude and Phase Maps}

The annual harmonics for the moorings (Figure 3 ) indicate a variety of amplitudes and phases. The largest amplitude, 1.0 , is near the west coast of Africa in the vicinity of the outlet of the Congo River. Other areas with large amplitude are in the Amazon River outflow in the western Atlantic, the western tropical Indian Ocean south of the equator and along $10^{\circ} \mathrm{N}$ in the North Pacific. The sizes of the harmonics shown match well with previous reported values [17-20]. Phases show maximum SSS in the northern hemisphere mostly in February-May and in the southern hemisphere in July-December (this will be shown more clearly below). There are some exceptions to this general pattern. The Bay of Bengal for example, has maximum SSS in October, and some far eastern North Pacific moorings also have a maximum SSS in October.
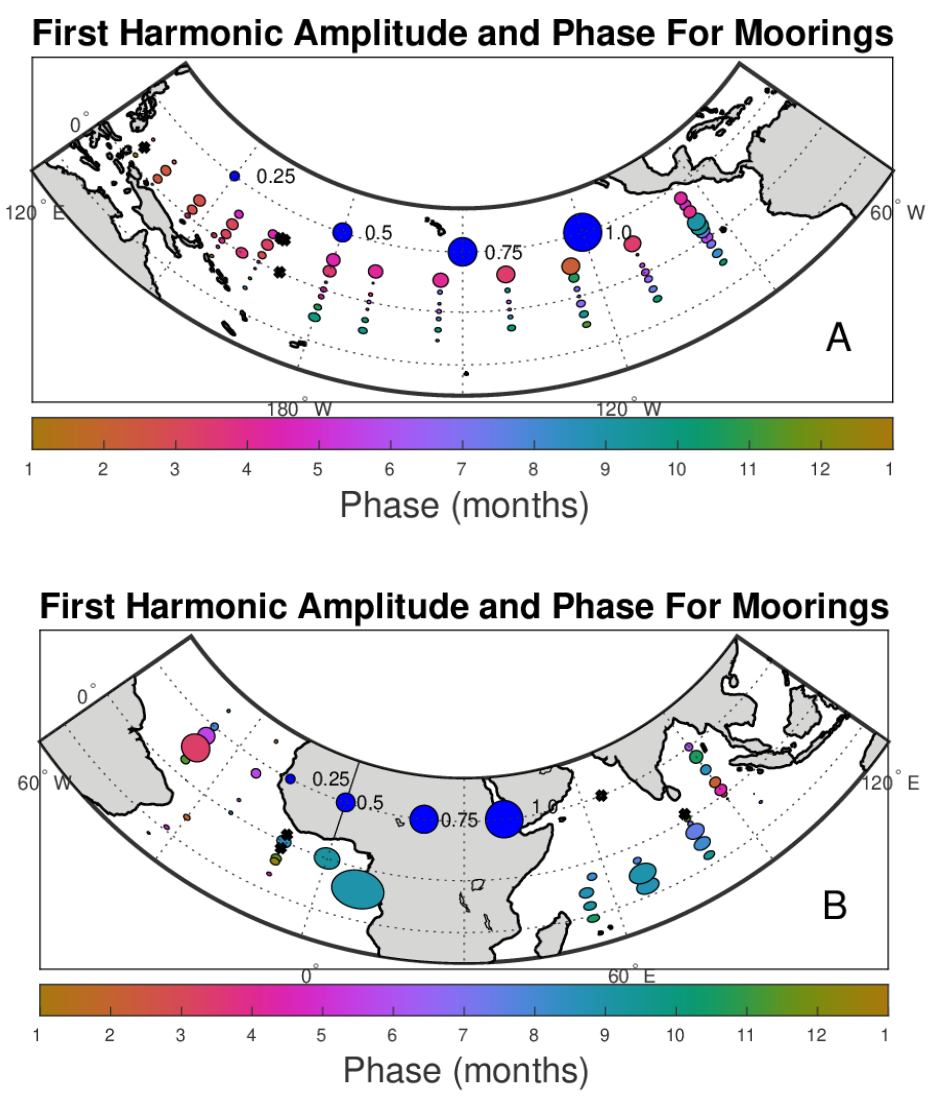

Figure 3. Amplitude and phase of the first harmonic from the moorings. Each symbol is for one mooring at its given location. The amplitude is indicated by the area of the symbol, with scale in dark blue near the top middle of each figure. The color of each symbol indicates the phase, as the month of maximum SSS, with color scale in months (January-January) at the bottom. Symbols with a black " $\mathrm{X}^{\text {" }}$ were either found not to have a significant fit to the annual harmonic, or contained less than one year of observations. The maps use an equal area conic projection. This means that though the symbols change in shape from north to south, the relative areas are depicted correctly in relation to the dark blue scale. (A) Pacific basin. (B) Atlantic and Indian basins. For completeness, we include maps of amplitude and phase for all products for both annual (Table S1) and semiannual (Table S4) harmonics. 
Next, we show maps of fraction of variance, $R^{2}$, explained by the harmonic fit (Figure 4). In the Pacific basin, the numbers tend to be larger, over 0.5, in the ITCZ, in the western Pacific and south of the equator in the eastern Pacific, whereas they are small along the equator. In the Atlantic most of the values are large, especially near the coast of Africa. In the Indian basin, the values get very large, approaching 1 in the western South Indian basin. All of these results indicate that in many parts of the tropical ocean, the seasonal time scale represents a large fraction of the total signal [20,21].
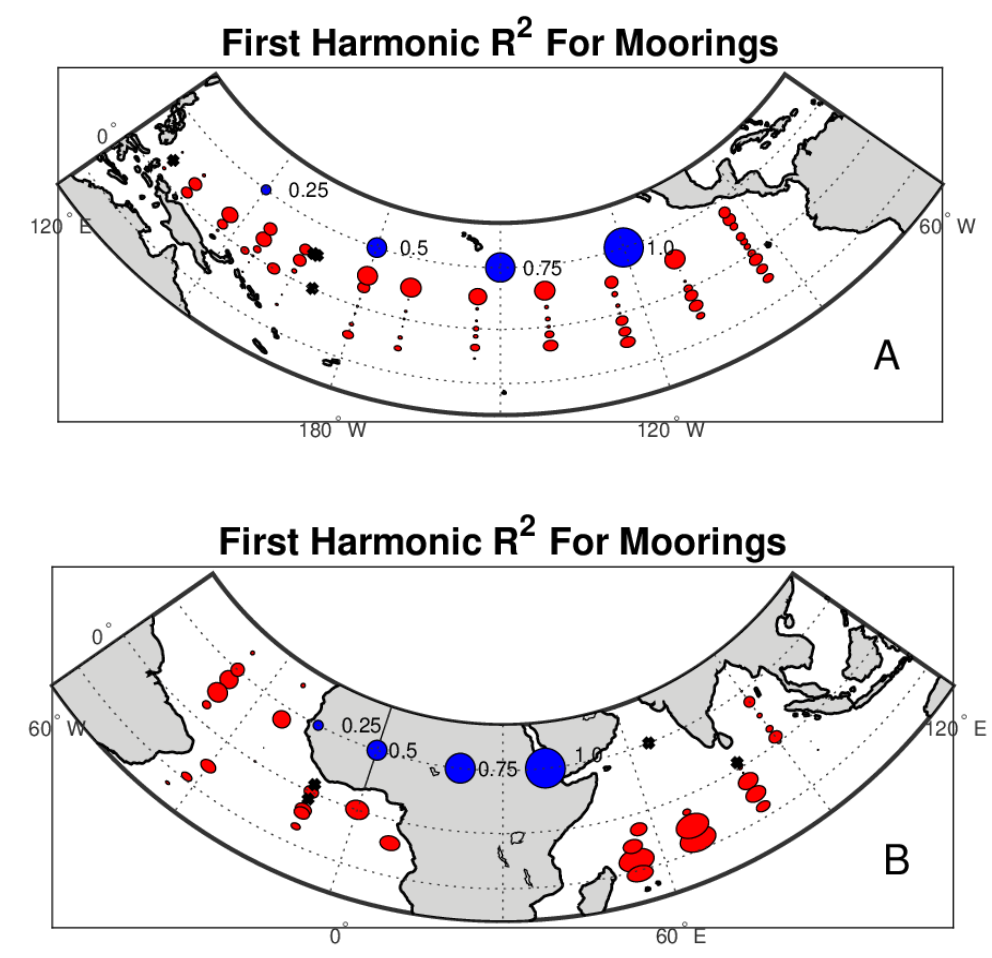

Figure 4. As in Figure 3, but for fraction of variance $\left(R^{2}\right)$ explained by the annual harmonic fit. For completeness, we include maps of $\mathrm{R}^{2}$ for all products for both annual (Table S2) and semiannual (Table S5) harmonics. (A) Pacific basin. (B) Atlantic and Indian basins.

The results presented in Figures 3 and 4 for the GTMBA are consistent with previous such calculations [17-19] using different datasets or [20] using mostly the same datasets. What we do differently here is to compare the various datasets against the moorings as ground truth, and to some extent each other. Analyses such as those of Figures 3 and 4 were carried out for all the different datasets mentioned in Section 2. We present a couple of examples similar to Figure 3 here and a more complete set of them in the supplemental materials.

The RSS SMAP amplitude and phase (Figure 5) are similar to the moorings with a few minor differences. In the western Pacific along the equator, the SMAP RSS data show a phase with maximum SSS in June, whereas in the mooring data those maxima are in March or so. The amplitudes are not large which may explain the difference. More of the SMAP RSS locations are below significance level than the moorings, especially off the equator in the central Pacific, likely due to the shorter record length. In the Atlantic and Indian basins, the results are also similar to the moorings. The results for $\mathrm{R}^{2}$ are also very similar, and are not included here for brevity, but are in the supplemental materials (Table S2).

The similarity of the mooring and SMAP RSS results is striking, and is repeated for most of the other datasets we analyzed (Tables S2 and S3). One exception is the SMOS BEC results shown in Figure 6. In this case there are major differences between these and the mooring data. The amplitudes are in general much smaller in the SMOS BEC data throughout the tropical ocean. Detailed comparison of the amplitudes and phases between the products and the moorings is presented below as a set of scatter plots and root mean square (RMS) differences. 


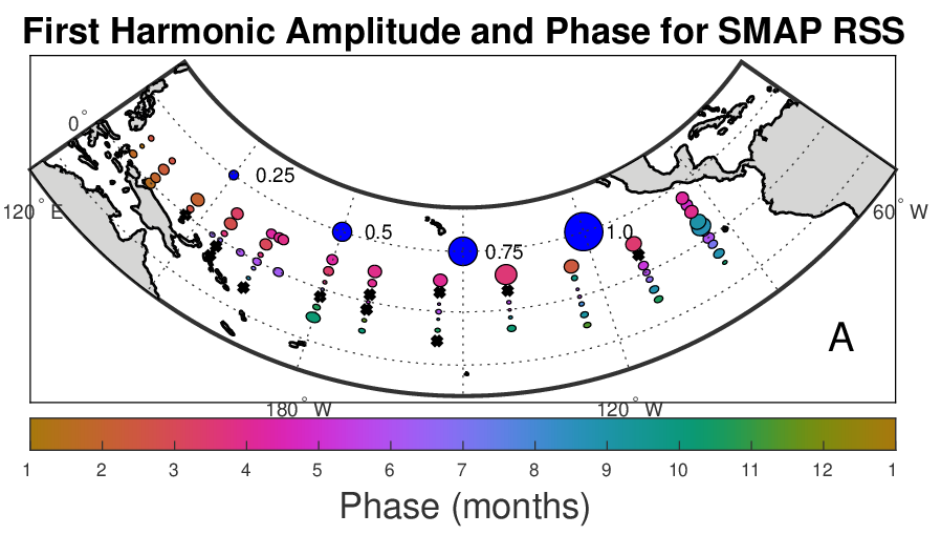

First Harmonic Amplitude and Phase for SMAP RSS

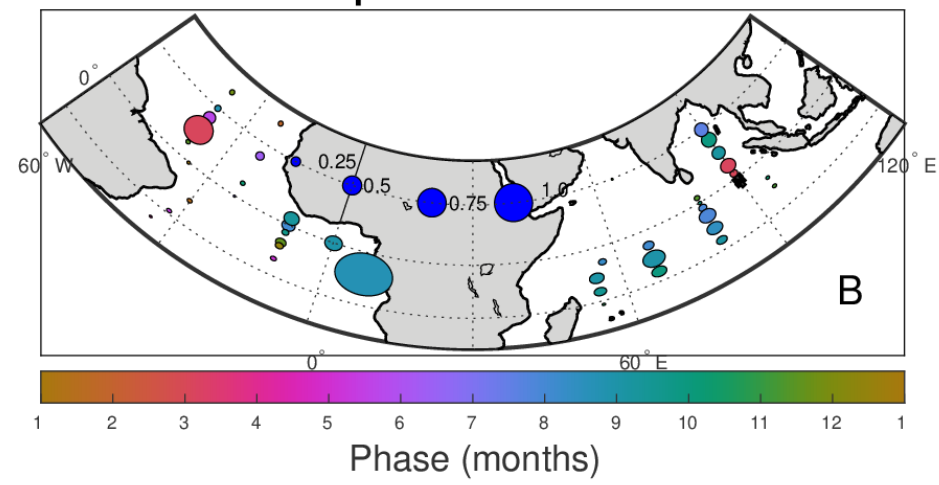

Figure 5. As in Figure 3, but for the SMAP RSS data. (A) Pacific basin. (B) Atlantic and Indian basins.

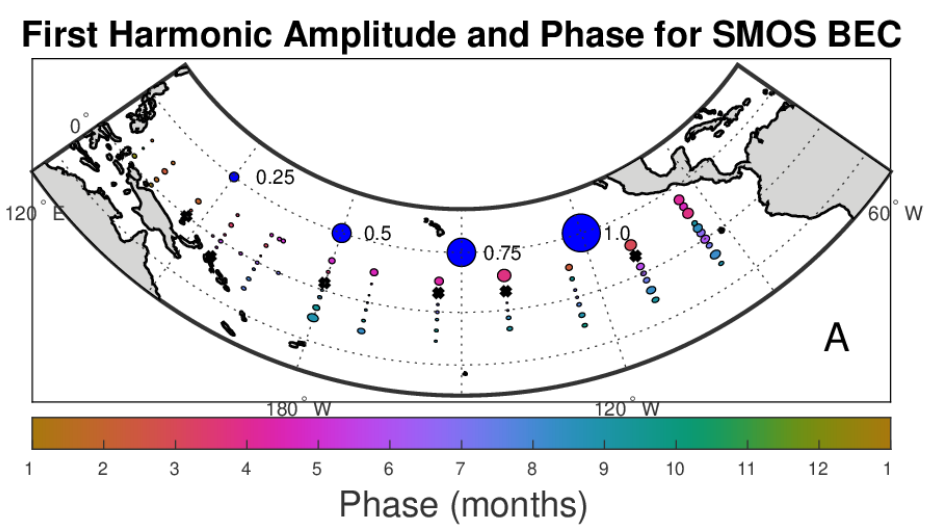

First Harmonic Amplitude and Phase for SMOS BEC

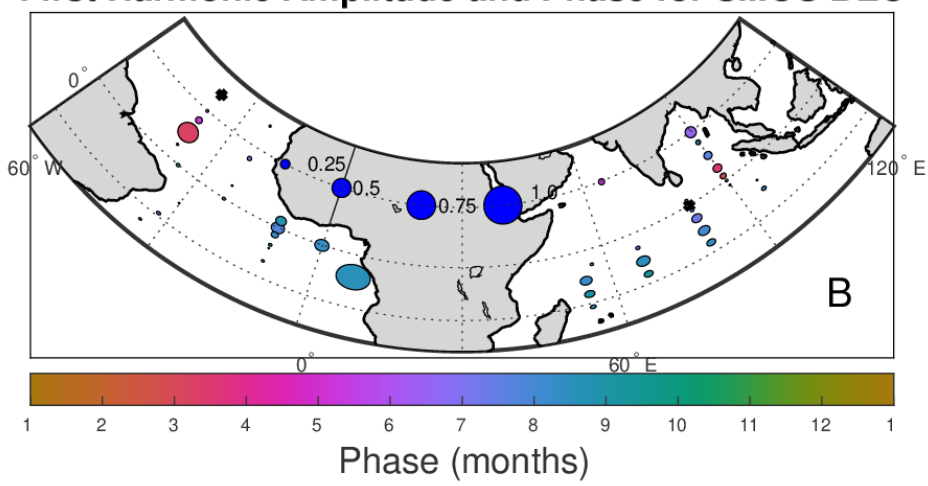

Figure 6. As in Figure 3, but for the SMOS BEC data. (A) Pacific basin. (B) Atlantic and Indian basins. 


\subsection{Amplitude and Phase Comparisons}

Comparison between mooring phases and the other datasets (Figure 7) show they mostly match well. Maximum SSS along the equator and at the southern hemisphere moorings is later in the year, July-December, while for the northern hemisphere moorings it is in February-May. There is some tendency for small amplitude locations to be further off the one-to-one correspondence line than large amplitude ones. RMS differences (RMSD) between mooring and product phase range from 0.5 to 1.5 months, all significantly different from zero (Table 2). Median differences are all less than or equal to 0.1 in absolute value and none of them are significantly different from zero. The datasets with the largest scatter are the two from SMAP (Figure 7A,B; 1.3 months RMSD), Aquarius (Figure 7C; also 1.3 months) and SMOS BEC (Figure 7F; 1.5 months). A bit less is the one from CCI (Figure 7D; 1.2 months) and the smallest are the two gridded in situ datasets (Figure 7G,H; 0.5 months).

In a couple of cases we can compare two products whose underlying measurement is the same. There are two different L3 SMAP products and two L3 SMOS products (Figure 8). So, in making these comparisons, all of the difference between them is due to the processing algorithm and not the measurement platform. The SMAP products compare very well, with an RMSD of about 0.7 months and median difference not significantly different from zero (Figure 8a). The one outlier point is at $\left(15^{\circ} \mathrm{N}, 65^{\circ} \mathrm{E}\right)$ in the Arabian Sea. (This harmonic is not included in any mooring plot because there are too few data at this location.) The two SMOS products do show some differences, with the SMOS BEC product generally leading the SMOS CATDS (Figure $8 \mathrm{~b}$ ). The median difference is 0.4 months, SMOS BEC leading, which is significantly different from zero.

With the first harmonic amplitudes, we find that most satellite and gridded in situ products compare well with the moorings (Figure 9 and Table 2). RMSDs are typically $0.07-0.08$ and median differences of about $0.01-0.03$. The two exceptions are Aquarius, with RMSD of 0.11 and SMOS BEC with RMSD of 0.13. For the SMOS BEC dataset, the mooring amplitudes are generally larger than in the satellite data, with median difference of about 0.06 .
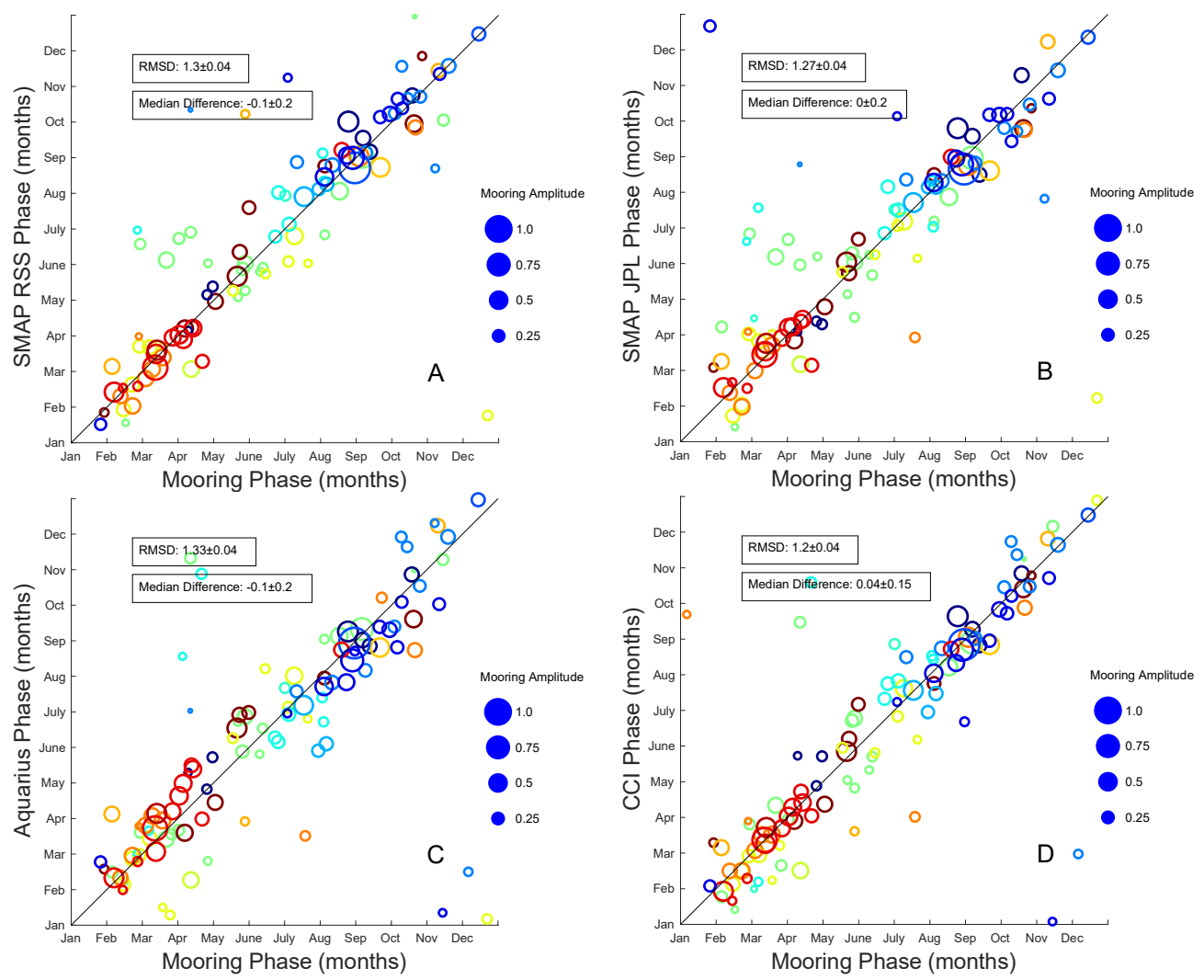

Figure 7. Cont. 


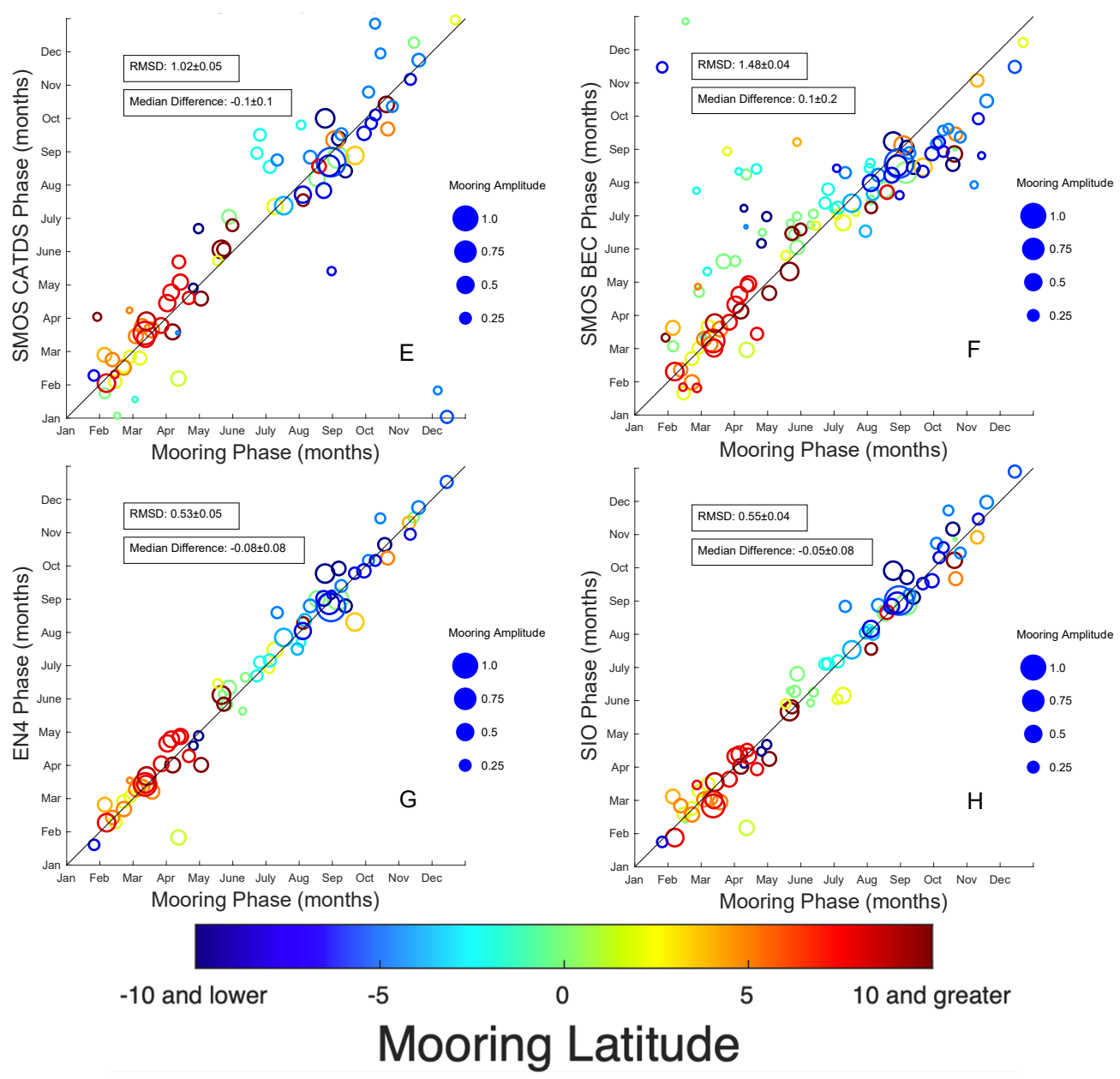

Figure 7. Scatterplots of first harmonic comparison product phase (month of maximum SSS) vs. mooring phase. Each symbol is for one mooring, with symbols plotted only where there is a significant annual fit for both the moorings and the given product. The number of symbols in each plot is given for each product in Table S6. Colors of symbols indicate latitude of mooring with scale at bottom. Sizes of symbols indicate mooring amplitude with scale at right in solid blue in each panel. A light black line shows a one-to-one correspondence. Boxes in each panel show root mean square differences (RMSD) and median difference (mooring-comparison) in months. Products compared are (A) SMAP RSS, (B) SMAP JPL, (C) Aquarius, (D) CCI, (E) SMOS CATDS, (F) SMOS BEC, (G) EN4, (H) SIO.
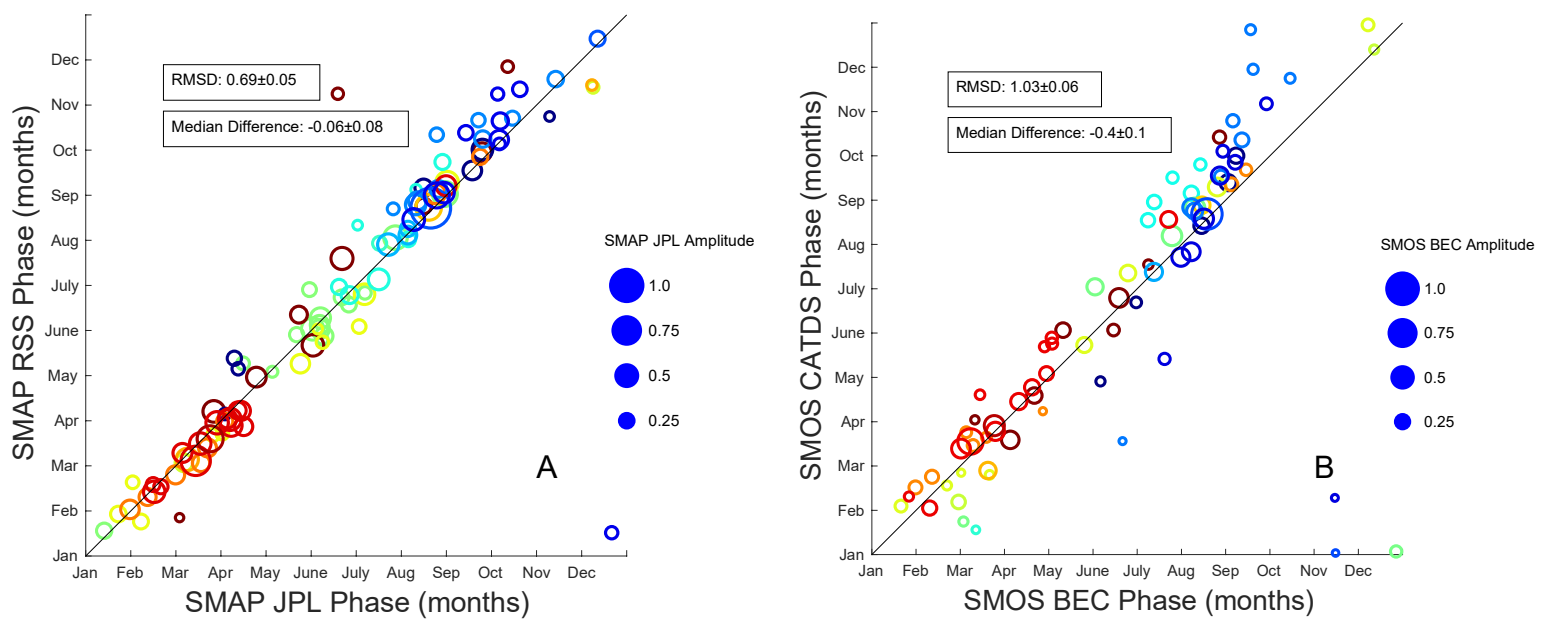

Figure 8. As in Figure 7. Comparisons are (A) SMAP RSS vs. SMAP JPL and (B) SMOS CATDS vs. SMOS BEC. 
Table 2. Columns 2-5: amplitude and phase discrepancies between mooring and satellite or gridded in situ products. Median differences are mooring-product. Column 6: median difference in $\mathrm{R}^{2}$ between mooring and satellite or in situ product for the annual harmonic. Positive number means mooring $\mathrm{R}^{2}$ is greater.

\begin{tabular}{|c|c|c|c|c|c|}
\hline Product & $\begin{array}{l}\text { Amplitude } \\
\text { RMSD }\end{array}$ & $\begin{array}{l}\text { Phase RMSD } \\
\text { (months) }\end{array}$ & $\begin{array}{c}\text { Amplitude Median } \\
\text { Difference }\end{array}$ & $\begin{array}{c}\text { Phase Median } \\
\text { Difference (months) }\end{array}$ & $\begin{array}{l}\mathrm{R}^{2} \text { Median } \\
\text { Difference }\end{array}$ \\
\hline SMOS BEC & $0.128 \pm 0.002$ & $1.48 \pm 0.04$ & $0.06 \pm 0.01$ & $-0.1 \pm 0.2$ & 0.03 \\
\hline SMOS CATDS & $0.085 \pm 0.004$ & $1.02 \pm 0.05$ & $0.01 \pm 0.01$ & $0.1 \pm 0.1$ & 0.05 \\
\hline $\mathrm{CCI}$ & $0.074 \pm 0.002$ & $1.2 \pm 0.04$ & $0.02 \pm 0.01$ & $-0.04 \pm 0.15$ & 0.01 \\
\hline SMAP JPL & $0.074 \pm 0.003$ & $1.27 \pm 0.04$ & $-0.013 \pm 0.009$ & $0.0 \pm 0.2$ & 0.01 \\
\hline SMAP RSS & $0.070 \pm 0.003$ & $1.30 \pm 0.04$ & $0.003 \pm 0.009$ & $0.1 \pm 0.2$ & 0.01 \\
\hline Aquarius & $0.108 \pm 0.003$ & $1.33 \pm 0.04$ & $-0.02 \pm 0.01$ & $0.1 \pm 0.2$ & -0.12 \\
\hline EN4 & $0.082 \pm 0.008$ & $0.53 \pm 0.05$ & $0.01 \pm 0.01$ & $0.08 \pm 0.08$ & -0.14 \\
\hline $\mathrm{SIO}$ & $0.080 \pm 0.008$ & $0.55 \pm 0.04$ & $0.01 \pm 0.01$ & $0.05 \pm 0.08$ & -0.14 \\
\hline
\end{tabular}

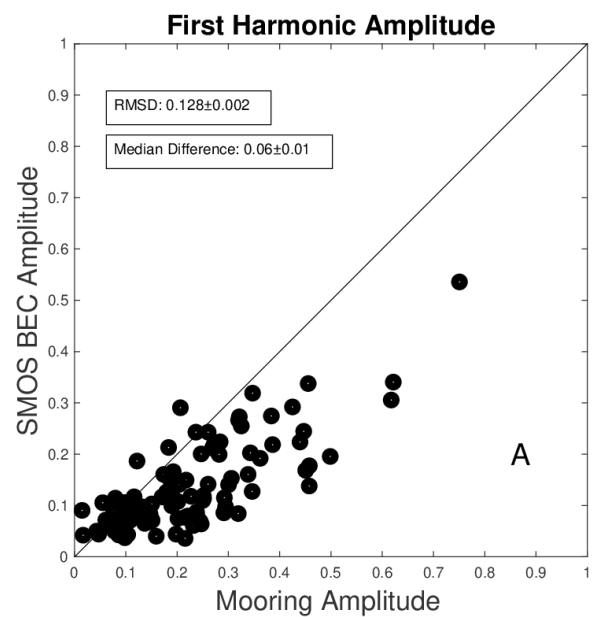

First Harmonic Amplitude

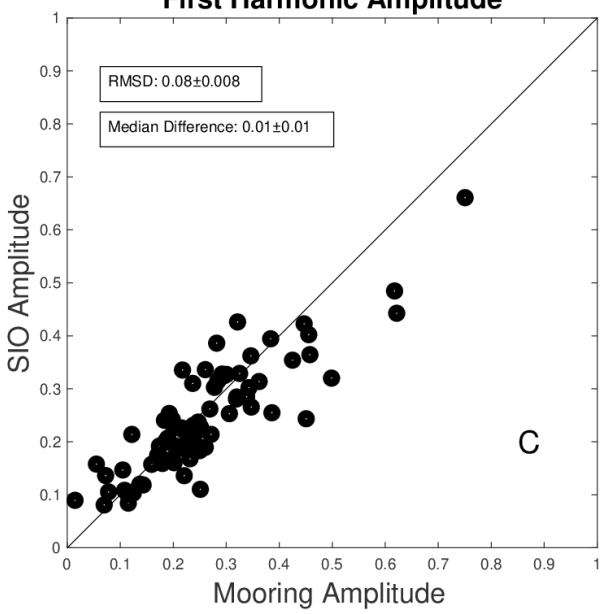

First Harmonic Amplitude

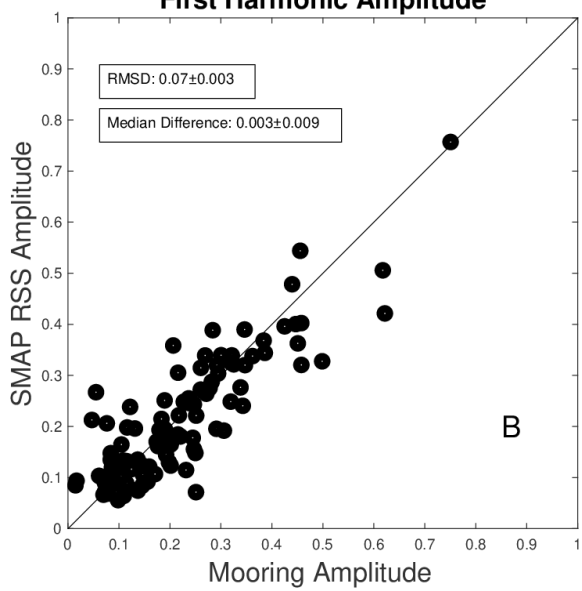

First Harmonic Amplitude

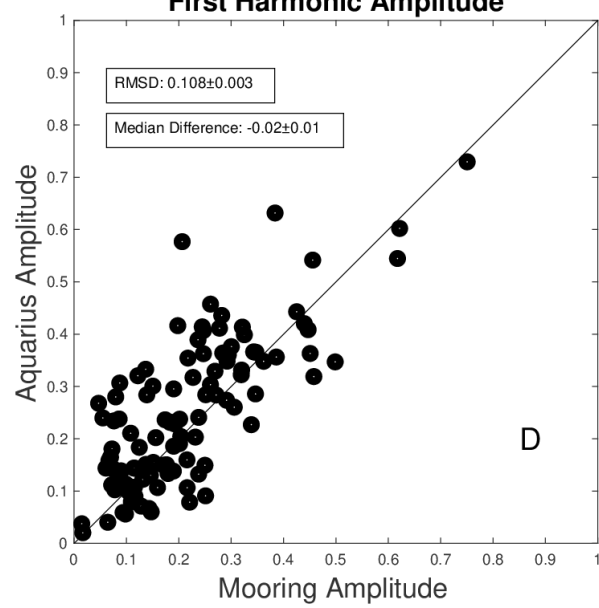

Figure 9. Scatterplots of first harmonic amplitude vs. mooring amplitude. A light black line shows a one-to-one correspondence. Boxes in each panel show RMSD and median difference (mooring-comparison). Comparison amplitudes are (A) SMOS BEC, (B) SMAP RSS, (C) SIO, (D) Aquarius. For completeness, all first harmonic amplitude comparisons are shown in the supplemental materials (Table S3).

Table 2 shows the median of the difference between $\mathrm{R}^{2}$ values for the mooring and that of the various products. In other words, for each dot in Figure 9, one can subtract the mooring value from the comparison product value, to obtain the degree to which those dots depart 
from the one-to-one line. One can then compute the median of those differences, to get the numbers displayed in Table 2. Table 3 shows the median over the dots for, say, the moorings or SMAP RSS. These values show which products tend to have large or small values of $\mathrm{R}^{2}$.

An example set of $\mathrm{R}^{2}$ comparisons are shown (Figure 10; Table 3 ). These examples were chosen to illustrate each of the satellites and one gridded in situ product. The value of $\mathrm{R}^{2}$ is a function of the temporal sampling of each dataset, and the footprint of the satellite or grid size of the in situ product. Overall, in the tropics the annual harmonic only comprises about $20 \%$ of the total variance of SSS for the moorings (Table 3 ). The moorings, one assumes as they are sampled hourly, capture all or almost all of the temporal variance in nature. The gridded in situ datasets (EN4 and SIO) are averaged monthly and over a $1^{\circ} \times 1^{\circ}$ area, so any variance with smaller time and space scales is not present in those datasets. Thus, one would expect $\mathrm{R}^{2}$ in the annual harmonic to be larger for these than for the moorings, which it is (Figure 10C; Table 3). For Aquarius, the issue is the same. It has a footprint similar in size to the in situ products' grids, generating an average over about a $100-\mathrm{km}$ area. Thus, it does not sample most of the variability at less than $100 \mathrm{~km}$ in size. As much of ocean SSS variance is at sizes less than $50 \mathrm{~km} \mathrm{[44],} \mathrm{the} \mathrm{Aquarius} \mathrm{dataset}$ cannot resolve it, and therefore, the annual harmonic constitutes a larger fraction of the variance than for the moorings (Figure 10D; Table 3). As we have seen, the SMOS BEC data underestimate the size of the annual harmonic, and so the fraction of variance captured in that dataset is less than for the moorings (Figure 10A; Table 3). Finally, the SMAP RSS product (Figure 10B; Table 3) has a smaller footprint than Aquarius, and more frequent sampling than SIO. The fraction of variance depicted in that dataset is comparable to that of the moorings. The datasets not plotted in Figure 10, SMOS CATDS, SMAP JPL, EN4 and CCI, all show similar patterns as SMAP RSS (Table 2).
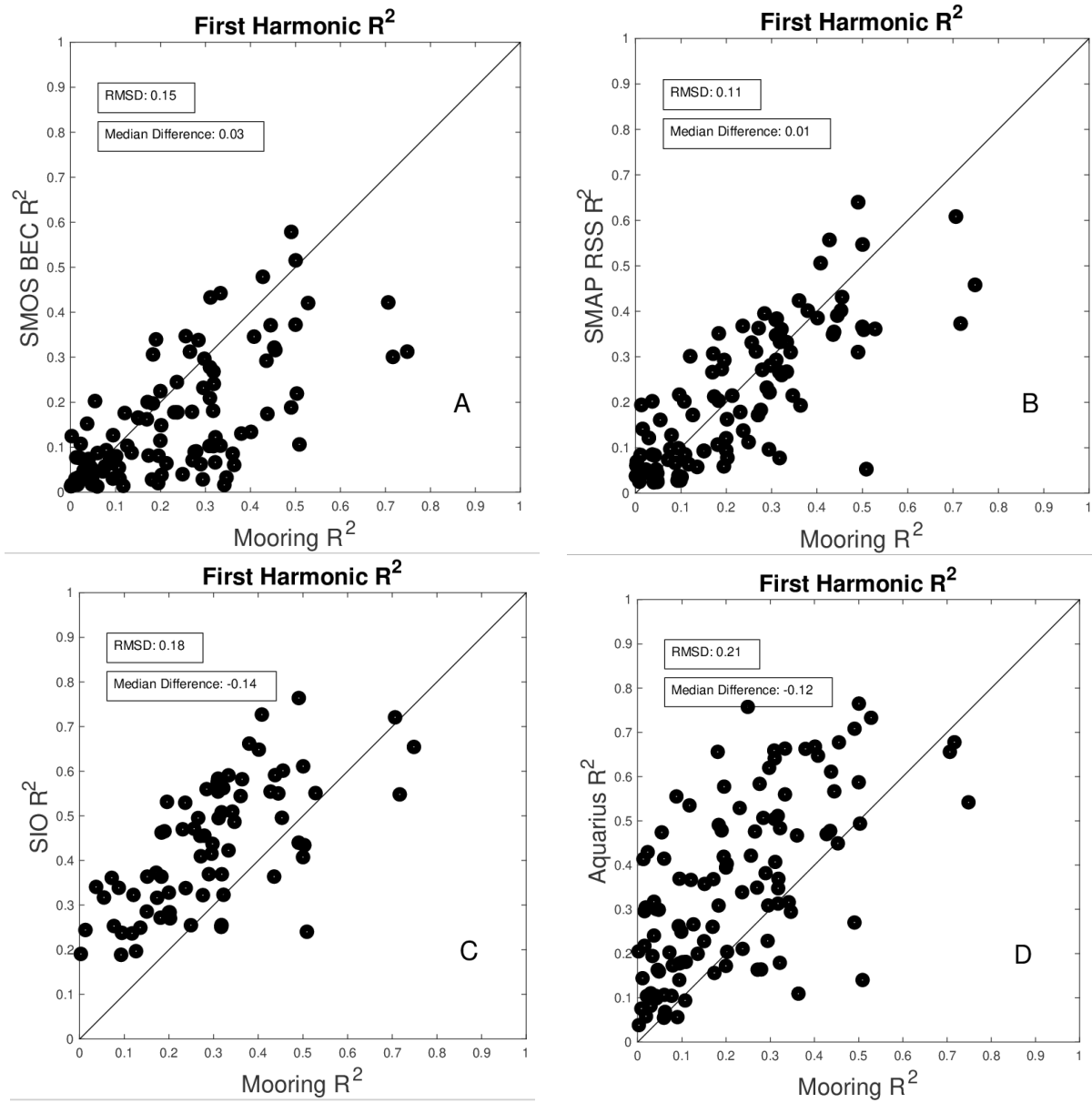

Figure 10. Scatterplots of fraction of variance, $\mathrm{R}^{2}$, in the annual harmonic captured by four products, compared to that captured by the moorings. $\mathrm{R}^{2}$ values are based on the entirety of each dataset, including possibly nonoverlapping periods. Products are (A) SMOS BEC, (B) SMAP RSS, (C) SIO and (D) Aquarius. 
Table 3. Median $\mathrm{R}^{2}$ over all the mooring locations for all the products for the annual harmonic. The number of mooring locations used in each of these values is listed in Table S6.

\begin{tabular}{cc}
\hline & Median $^{\mathbf{2}}$ \\
\hline Moorings & 0.190 \\
SMOS BEC & 0.103 \\
SMOS CATDS & 0.187 \\
CCI & 0.1842 \\
SMAP JPL & 0.198 \\
SMAP RSS & 0.203 \\
Aquarius & 0.316 \\
EN4 & 0.351 \\
SIO & 0.430 \\
\hline
\end{tabular}

\section{Discussion}

We have done comparisons of various SSS datasets at the annual time scale. These comparisons are congruent with those of many previous studies [17-20]. The advantage to our analysis is that it was done with the very long, high-quality records of SSS at the moorings, and that these mooring data are largely independent of the products being evaluated. We have done more detailed comparisons of amplitude (Figure 9) and phase (Figure 7) in the discrete locations defined by the moorings (Figure 1) than was done by Yu et al. [20] or any previous studies. The disadvantage is the limited geographical expanse of the mooring array-most are equatorward of $10^{\circ}$ especially in the Pacific, and the limited coverage of a point measurement from a mooring relative to the spatial averages from a satellite or gridded in situ product [45].

Most of the datasets record the phase of the annual cycle in a way that is reasonably consistent with the mooring data. Median phase differences between moorings and the products studied all include zero in their uncertainty range (Table 2, column 5 and Figure 7). The RMSD for phase between the moorings and the different products varies between 0.5 and 1.5 (Table 2, column 3 and Figure 7), giving an idea of the spread of phase values inherent in the data. Most of the products studied also give a reasonable value for the amplitude. Amplitude median differences are as high as 0.06 (Table 2, column 4), with some within the uncertainty range of zero.

It is difficult to track what exactly might be causing differences in products quantified in Table 2 given the variety of different processing algorithms, hardware configurations, antenna patterns, ancillary input data, etc. detailed in the references shown in Table 1 and summarized in Reul et al. [31]. Are differences related to the conversion from L2 to L3? Is the annual cycle the same or similar in the L2 version of each of these as in the L3? Are any differences inherent in the hardware that is in orbit or are they part of the processing algorithm that converts engineering measurements within the satellite to geophysical measurements (L1 to L2)? Are they related to the footprint of the satellite or its antenna pattern? Its method of correcting for sea state, Faraday rotation within the atmosphere, galaxy brightness, radio frequency interference filtering, etc.? We get some hint of the answers to these questions in the comparison of SMAP RSS and SMAP JPL (Figure 8a) and comparison of SMOS BEC and SMOS CATDS (Figure $8 b$ ). As these datasets originate from the same basic L1 observations, any differences must be related to the L1 to L2 or L2 to L3 conversion. In the case of SMAP, it appears that very little difference is introduced in the gridding and processing, but the opposite is the case with the SMOS datasets. Clearly answers to the questions posed in this paragraph will require more analysis.

Another issue to consider when interpreting the results presented here is the depth dependence of upper ocean salinity, and how it is measured. There is a mismatch of sampling between these three measurement systems in depth. Satellites measure the skin surface value, the upper $1-2 \mathrm{~cm}$. Argo floats, from which the EN4 and SIO products are mainly derived, usually do not measure above $5 \mathrm{~m}$ depth [15]. The topmost salinity sensors on the GTMBA buoys are positioned much closer to the surface, at a depth of 
$\sim 1 \mathrm{~m}$ [35]. The issue of depth dependence of upper ocean salinity has been explored in many previous papers $[15,46-50]$. What impact might this different sampling have had on the results presented here? The moorings, having sensors close to the surface, give a better estimate of near surface values than Argo floats would. Studies like Drushka et al. [43] have shown that rain anomalies do tend to get concentrated in the upper meter of the ocean surface. Such anomalies are present in the mooring time series like those displayed in Figure 2A. On the other hand, the large footprint of SSS satellites would tend to suppress short time scale, rain-induced SSS anomalies. So, one would guess that the mooring time series will be able to capture very low values during rain events that might not be present in the footprint-averaged satellite values or the gridded in situ data. This effect is quite visible in Figure 2D. This could potentially lead to the mooring data having larger seasonal amplitudes than the other two types of data as low outliers during rainy seasons influence the harmonic analysis we have done here. However, this does not seem to be the case, at least for most of the products (Figure 9B-D and Table 2).

Satellite SSS is usually validated against one of the common gridded in situ products $[5,7,20,30]$, of which we utilized two for our work here. As the seasonal time scale is one of the most energetic in terms of variability [21], it is important to make sure these products themselves are validated. We have done some of that here for a limited geographical extent and a very limited time scale-i.e., annual.

Most important for the process of validation is the different fractions of temporal variance captured in the annual time scale by the gridded in situ products vs. the various satellite products (Table 3 and Figure 10). Given the fact that gridded in situ products are mostly generated from sparse Argo data, it is expected that the seasonal time scale would be more heavily represented than anything shorter. Our results show however, that if validation is done using gridded products, important parts of the temporal spectrum of variability are missing. Do the satellite products get the balance correct between seasonal and shorter-term variability? Our results from Table 3 and Figure 10 show that this varies from one product to another.

As the moorings are a directly-measured, non-gridded in situ dataset, the value of $R^{2}$ presented in Table 3 (0.19) likely is a good estimate of what fraction of variance the annual cycle represents in the real ocean-though Figure 10 indicates that this has a large degree of variation, from near-zero to almost $80 \%$. A further extension on this study would be to use the mooring data to generate power spectra for each location to see how prominent the peaks are, and how those spectra compare with ones from the satellite data. A major difference between the satellite data and the moorings is the fact that the satellites measure over a footprint rather than at a point. One would expect this difference to reduce the variance in individual estimates of SSS and thus make spectral peaks, including a seasonal peak if present, more prominent. Table 3 shows that the fraction of variance in the mooring data is larger than one of the satellite datasets (SMOS BEC), comparable to most, and smaller than one (Aquarius). This seems a hopeful sign, that the satellite datasets are mostly doing well at capturing the seasonal cycle, or at least giving it the correct weight among the other time scales present in the ocean.

\section{Conclusions}

We have compared a variety of satellite and gridded in situ products with SSS data from the GTMBA at the seasonal time scale. A summary of the important results of this paper is shown in Table 2, which gives RMSD and median difference (i.e., bias) relative to the GTMBA for each product. The annual cycle is generally well-represented in all the products, though some discrepancies have been highlighted in the text. RMSD in amplitude (phase) has a range of $0.07-0.13$ (0.5-1.5 months). Bias has a range of $-0.02-0.06$ ( $-0.1-0.1$ months) in amplitude (phase). All values of phase difference include zero in their uncertainty range. The different products have different characteristics with regards to the fraction of variance in the annual cycle (Table 3). Aquarius and the two gridded in situ products have the largest fraction (up to $43 \%$ ) and the SMOS BEC product the smallest (10\%). 
Supplementary Materials: The following are available online at https:/ / www.mdpi.com/2072-429 2/13/1/110/s1, Tables S1-S6.

Author Contributions: Conceptualization: F.M.B. and L.Y.; formal analysis: S.B.; funding acquisition: F.M.B.; project administration: F.M.B.; software: F.M.B. and S.B.; supervision: F.M.B.; visualization: S.B.; writing-original draft: F.M.B. and S.B.; writing—review and editing: F.M.B. and L.Y. All authors have read and agreed to the published version of the manuscript.

Funding: This research was funded by the National Aeronautics and Space Administration under grant number 80NSSC18K1322.

Informed Consent Statement: Not applicable.

Data Availability Statement: Data used in this study are available at the following locations.

\begin{tabular}{|c|c|c|}
\hline Dataset & URL/DOI & Example File Name \\
\hline Moorings & https://www.pmel.noaa.gov/tao/drupal/disdel/ & $\mathrm{N} / \mathrm{A}$ \\
\hline SMOS BEC & http://bec.icm.csic.es/ocean-global-sss/ & $\begin{array}{l}\text { BEC_SSS_SMOS_GLO_L3_B_B_ } \\
\text { 20110124T120000_0.25d_9d_REP_v002.nc }\end{array}$ \\
\hline SMOS CATDS & DOI:10.17882/52804 & $\begin{array}{c}\text { SMOS_L3_DEBIAS_LOCEAN_AD_20100116_ } \\
\text { EASE_09d_25km_v04.nc }\end{array}$ \\
\hline CCI & DOI:10.5285/9ef0ebf847564c2eabe62cac4899ec41 & $\begin{array}{l}\text { ESACCI-SEASURFACESALINITY-L4-SSS- } \\
\text { MERGED_OI_7DAY_RUNNINGMEAN_DAILY_ } \\
\text { 25km-20100101-fv2.31.nc }\end{array}$ \\
\hline SMAP JPL & DOI:10.5067/SMP43-3TPCS & SMAP_L3_SSS_20150627_8DAYS_V4.3.nc \\
\hline SMAP RSS (70 km) & DOI:10.5067/SMP40-3SPCS & $\begin{array}{l}\text { RSS_smap_SSS_L3_8day_running_2015_090_FNL_ } \\
\text { v04.0.nc }\end{array}$ \\
\hline Aquarius & DOI:10.5067/AQR50-3YQCE & $\begin{array}{l}\text { Q20112312011237.L3m_R7_SCI_V5.0.RAIN_ } \\
\text { MASK_SSS_1deg }\end{array}$ \\
\hline EN4 & https://www.metoffice.gov.uk/hadobs/en4/ & EN.4.2.1.f.analysis.g10.200001.nc \\
\hline $\mathrm{SIO}$ & http://sio-argo.ucsd.edu/RG_Climatology.html & RG_ArgoClim_Psal.nc \\
\hline
\end{tabular}

Acknowledgments: The authors are grateful for the comments and suggestions of four anonymous reviewers and NASA's Ocean Salinity Science Team. SMAP salinity data are produced by Remote Sensing Systems and sponsored by the NASA Ocean Salinity Science Team. They are available at www.remss.com. GTMBA data were provided through the GTMBA Project Office of NOAA/PMEL. The L3_DEBIAS_LOCEAN_v4 Sea Surface Salinity maps have been produced by LOCEAN/IPSL (UMR CNRS/SU/IRD/MNHN) laboratory and ACRI-st company that participate to the Ocean Salinity Expertise Center (CEC-OS) of Centre Aval de Traitement des Donnees SMOS (CATDS). This product is distributed by the Ocean Salinity Expertise Center (CEC-OS) of the CNES-IFREMER Centre Aval de Traitemenent des Donnees SMOS (CATDS), at IFREMER, Plouzane (France). Color scales are taken from the "cmocean" package [51].

Conflicts of Interest: The authors declare no conflict of interest.

\section{References}

1. Kerr, Y.H.; Waldteufel, P.; Wigneron, J.-P.; Delwart, S.; Cabot, F.; Boutin, J.; Escorihuela, M.-J.; Font, J.; Reul, N.; Gruhier, C.; et al. The SMOS Mission: New Tool for Monitoring Key Elements ofthe Global Water Cycle. Proc. IEEE 2010, 98, 666-687. [CrossRef]

2. Lagerloef, G.; Colomb, F.R.; Le Vine, D.; Wentz, F.; Yueh, S.; Ruf, C.; Lilly, J.; Gunn, J.; Chao, Y.; Decharon, A.; et al. The Aquarius/SAC-D Mission: Designed to Meet the Salinity Remote-Sensing Challenge. Oceanography 2008, 21, 68-81. [CrossRef]

3. Meissner, T.; Wentz, F.J.; Le Vine, D.M. The Salinity Retrieval Algorithms for the NASA Aquarius Version 5 and SMAP Version 3 Releases. Remote Sens. 2018, 10, 1121. [CrossRef]

4. Abe, H.; Ebuchi, N. Evaluation of sea-surface salinity observed by Aquarius. J. Geophys. Res. Oceans 2014, 119, 8109-8121. [CrossRef]

5. Bao, S.; Wang, H.; Li, M.; Yan, H.; Chen, J. Comparison of Satellite-Derived Sea Surface Salinity Products from SMOS, Aquarius, and SMAP. J. Geophys. Res. Oceans 2019, 124, 1932-1944. [CrossRef] 
6. Vazquez-Cuervo, J.; Gomez-Valdes, J.; Bouali, M.; Miranda, L.E.; Van Der Stocken, T.; Tang, W.; Gentemann, C.L. Using Saildrones to Validate Satellite-Derived Sea Surface Salinity and Sea Surface Temperature along the California/Baja Coast. Remote Sens. 2019, 11, 1964. [CrossRef]

7. Kao, H.; Lagerloef, G.; Lee, T.; Melnichenko, O.; Meissner, T.; Hacker, P. Assessment of Aquarius Sea Surface Salinity. Remote Sens. 2018, 10, 1341. [CrossRef]

8. Kao, H.-Y.; Lagerloef, G.; Lee, T.; Melnichenko, O.; Hacker, P. Aquarius Salinity Validation Analysis; Data Version 5.0; Aquarius/SACD: Seattle, WA, USA, 2018; p. 45.

9. Olmedo, E.; Martinez, J.; Turiel, A.; Ballabrera-Poy, J.; Portabella, M. Debiased non-Bayesian retrieval: A novel approach to SMOS Sea Surface Salinity. Remote Sens. Environ. 2017, 193, 103-126. [CrossRef]

10. Olmedo, E.; González-Haro, C.; Hoareau, N.; Umbert, M.; González-Gambau, V.; Martínez, J.; Gabarró, C.; Turiel, A. Nine years of SMOS Sea Surface Salinity global maps at the Barcelona Expert Center. Earth Syst. Sci. Data Discuss. 2020, 2020, 1-49. [CrossRef]

11. Dinnat, E.; Le Vine, D.M.; Boutin, J.; Meissner, T.; Lagerloef, G. Remote Sensing of Sea Surface Salinity: Comparison of Satellite and In Situ Observations and Impact of Retrieval Parameters. Remote Sens. 2019, 11, 750. [CrossRef]

12. Qin, S.; Wang, H.; Zhu, J.; Wan, L.; Zhang, Y.; Wang, H. Validation and correction of sea surface salinity retrieval from SMAP. Acta Oceanol. Sin. 2020, 39, 148-158. [CrossRef]

13. Tang, W.; Fore, A.G.; Yueh, S.; Lee, T.; Hayashi, A.; Sanchez-Franks, A.; Martinez, J.; King, B.; Baranowski, D. Validating SMAP SSS with in situ measurements. Remote Sens. Environ. 2017, 200, 326-340. [CrossRef]

14. Roemmich, D.; Gilson, J. The 2004-2008 mean and annual cycle of temperature, salinity, and steric height in the global ocean from the Argo Program. Prog. Oceanogr. 2009, 82, 81-100. [CrossRef]

15. Drucker, R.; Riser, S.C. Validation of Aquarius sea surface salinity with Argo: Analysis of error due to depth of measurement and vertical salinity stratification. J. Geophys. Res. Oceans 2014, 119, 4626-4637. [CrossRef]

16. Kuusela, M.; Stein, M.L. Locally stationary spatio-temporal interpolation of Argo profiling float data. Proc. R. Soc. A 2018, 474, 20180400. [CrossRef] [PubMed]

17. Bingham, F.M.; Foltz, G.R.; McPhaden, M.J. Seasonal cycles of surface layer salinity in the Pacific Ocean. Ocean Sci. 2010, 6, 775-787. [CrossRef]

18. Bingham, F.M.; Foltz, G.R.; McPhaden, M.J. Characteristics of the seasonal cycle of surface layer salinity in the global ocean. Ocean Sci. 2012, 8, 915-929. [CrossRef]

19. Boyer, T.; Levitus, S. Harmonic analysis of climatological sea surface salinity. J. Geophys. Res. Space Phys. 2002, 107, 8006. [CrossRef]

20. Yu, L.; Bingham, F.M.; Dinnat, E.; Fournier, S.; Lee, T.; Melnichenko, O. Seasonality in Sea Surface Salinity Revisited. J. Geophys. Res. Ocean. 2020. in review.

21. Bingham, F.M.; Lee, T. Space and time scales of sea surface salinity and freshwater forcing variability in the global ocean $\left(60^{\circ} \mathrm{S}-60^{\circ} \mathrm{N}\right)$. J. Geophys. Res. Oceans 2017, 122, 2909-2922. [CrossRef]

22. Martins, M.S.; Serra, N.; Stammer, D. Spatial and temporal scales of sea surface salinity variability in the Atlantic Ocean. J. Geophys. Res. Oceans 2015, 120, 4306-4323. [CrossRef]

23. Melnichenko, O.; Hacker, P.; Bingham, F.M.; Lee, T. Patterns of SSS Variability in the Eastern Tropical Pacific: Intraseasonal to Interannual Timescales from Seven Years of NASA Satellite Data. Oceanography 2019, 32, 20-29. [CrossRef]

24. Kessler, W. The circulation of the eastern tropical Pacific: A review. Prog. Oceanogr. 2006, 69, 181-217. [CrossRef]

25. Guimbard, S.; Reul, N.; Chapron, B.; Umbert, M.; Maes, C. Seasonal and interannual variability of the Eastern Tropical Pacific Fresh Pool. J. Geophys. Res. Oceans 2017, 122, 1749-1771. [CrossRef]

26. Fiedler, P.C.; Talley, L.D. Hydrography of the eastern tropical Pacific: A review. Prog. Oceanogr. 2006, 69, 143-180. [CrossRef]

27. Foltz, G.R.; McPhaden, M.J. Seasonal mixed layer salinity balance of the tropical North Atlantic Ocean. J. Geophys. Res. Space Phys. 2008, 113, 02013. [CrossRef]

28. Grodsky, S.A.; Carton, J.A.; Bryan, F.O. A curious local surface salinity maximum in the northwestern tropical Atlantic. J. Geophys. Res. Ocean. 2014, 119, 484-495. [CrossRef]

29. McPhaden, M.; Busalacchi, A.; Anderson, D. A TOGA Retrospective. Oceanography 2010, 23, 86-103. [CrossRef]

30. Tang, W.; Yueh, S.H.; Fore, A.G.; Hayashi, A.; Lee, T.; Lagerloef, G. Uncertainty of Aquarius sea surface salinity retrieved under rainy conditions and its implication on the water cycle study. J. Geophys. Res. Ocean. 2014, 119, 4821-4839. [CrossRef]

31. Reul, N.; Grodsky, S.; Arias, M.; Boutin, J.; Catany, R.; Chapron, B.; D'Amico, F.; Dinnat, E.; Donlon, C.; Fore, A.; et al. Sea surface salinity estimates from spaceborne L-band radiometers: An overview of the first decade of observation (2010-2019). Remote Sens. Environ. 2020, 242, 111769. [CrossRef]

32. Good, S.A.; Martin, M.J.; Rayner, N.A. EN4: Quality controlled ocean temperature and salinity profiles and monthly objective analyses with uncertainty estimates. J. Geophys. Res. Oceans 2013, 118, 6704-6716. [CrossRef]

33. Meissner, T.; Wentz, F.; Manaseter, A. Remote Sensing Systems SMAP Ocean Surface Salinities Level 3 Running 8-Day; Version 3.0 validated release; Systems, R.S., Ed.; Remote Sensing Systems: Santa Rosa, CA, USA, 2018.

34. Millero, F.J. What is PSU? Oceanography 1993, 6, 67.

35. Freitag, H.P.; McPhaden, M.J.; Connell, K.J. Comparison of ATLAS and T-FLEX Mooring Data. Available online: https://www. pmel.noaa.gov / pubs/PDF/frei4747 / frei4747.pdf (accessed on 24 December 2020). 
36. Olmedo, E.; González-Haro, C.; González-Gambau, V.; Martínez, J.; Turiel, A. Global SMOS-BEC SSS L3 and L4 Product V2 Description. Available online: http:/ / bec.icm.csic.es/doc/BEC-SMOS-PD-SSSv2-v1.pdf (accessed on 24 December 2020).

37. Boutin, J.; Vergely, J.-L.; Khvorostyanov, D. SMOS SSS L3 maps generated by CATDS CEC LOCEAN. debias V5.0. Available online: https://www.seanoe.org/data/00417/52804/ (accessed on 24 December 2020).

38. Boutin, J.; Vergely, J.; Marchand, S.; D'Amico, F.; Hasson, A.; Kolodziejczyk, N.; Reul, N.; Reverdin, G.; Vialard, J. New SMOS Sea Surface Salinity with reduced systematic errors and improved variability. Remote Sens. Environ. 2018, 214, 115-134. [CrossRef]

39. Vergely, J.-L.; Boutin, J. SMOS OS Level 3 Algorithm Theoretical Basis Document (v300). Available online: https://www.catds.fr/ content/download/78841/file/ATBD_L3OS_v3.0.pdf (accessed on 24 December 2020).

40. Rouffi, F. Climate Change Initiative+ (CCI+) Phase 1: Sea Surface Salinity [D4.3] Product User Guide. Available online: https:/ / res.mdpi.com/data/mdpi_references_guide_v5.pdf (accessed on 24 December 2020).

41. Fore, A.; Yueh, S.; Tang, W.; Hayashi, A. SMAP Salinity and Wind Speed Users Guide, Version 5.0. Available online: https: / / podaac-tools.jpl.nasa.gov/drive/files/allData/smap/docs/\%20JPL-CAP_V5/SMAP-SSS_JPL_V5.0_Documentation.pdf (accessed on 30 December 2020).

42. Yi, D.L.; Melnichenko, O.; Hacker, P.; Potemra, J. Remote Sensing of Sea Surface Salinity Variability in the South China Sea. J. Geophys. Res. Oceans 2020, 125, e2020JC016827. [CrossRef]

43. Drushka, K.; Asher, W.; Jessup, A.; Thompson, E.; Iyer, S.; Clark, D. Capturing Fresh Layers with the Surface Salinity Profiler. Oceanography 2019, 32, 76-85. [CrossRef]

44. D'Addezio, J.M.; Bingham, F.M.; Jacobs, G.A. Sea surface salinity subfootprint variability estimates from regional high-resolution model simulations. Remote Sens. Environ. 2019, 233, 111365. [CrossRef]

45. Bingham, F.M. Subfootprint Variability of Sea Surface Salinity Observed during the SPURS-1 and SPURS-2 Field Campaigns. Remote Sens. 2019, 11, 2689. [CrossRef]

46. Boutin, J.; Martin, N.; Reverdin, G.; Yin, X.; Gaillard, F. Sea surface freshening inferred from SMOS and ARGO salinity: Impact of rain. Ocean Sci. 2013, 9, 183-192. [CrossRef]

47. Boutin, J.; Chao, Y.; Asher, W.E.; Delcroix, T.; Drucker, R.; Drushka, K.; Kolodziejczyk, N.; Lee, T.; Reul, N.; Reverdin, G.; et al. Satellite and In Situ Salinity: Understanding Near-Surface Stratification and Subfootprint Variability. Bull. Am. Meteorol. Soc. 2016, 97, 1391-1407. [CrossRef]

48. Hénocq, C.; Boutin, J.; Reverdin, G.; Petitcolin, F.; Arnault, S.; Lattes, P. Vertical Variability of Near-Surface Salinity in the Tropics: Consequences for L-Band Radiometer Calibration and Validation. J. Atmospheric Ocean. Technol. 2010, 27, 192-209. [CrossRef]

49. Rainville, L.; Centurioni, L.; Asher, W.; Clayson, C.A.; Drushka, K.; Edson, J.; Hodges, B.; Hormann, V.; Farrar, J.T.; Schanze, J.J.; et al. Novel and Flexible Approach to Access the Open Ocean: Uses of Sailing Research Vessel Lady Amber During SPURS-2. Oceanography 2019, 32, 116-121. [CrossRef]

50. Drushka, K.; Asher, W.E.; Sprintall, J.; Gille, S.T.; Hoang, C. Global Patterns of Submesoscale Surface Salinity Variability. J. Phys. Oceanogr. 2019, 49, 1669-1685. [CrossRef]

51. Thyng, K.; Greene, C.; Hetland, R.; Zimmerle, H.; DiMarco, S. True Colors of Oceanography: Guidelines for Effective and Accurate Colormap Selection. Oceanography 2016, 29, 9-13. [CrossRef] 